\title{
Effect of Smartphone Addiction on Craniovertebral Angle and Muscle Fatigue of Cervical Erector Spinae and Upper Trapezius
}

\author{
Kejal Manoj Pardeshi*, Manasi Patel, Amrutkuvar Rayjade, Trupti Yadav and Khusbhoo Chotai \\ Department of Physiotherapy, Krishna Institute of Medical Sciences "Deemed to be" University, \\ Karad-415110, Maharashtra, India; kejal.pardeshi@gmail.com
}

\begin{abstract}
India ranks $3^{\text {rd }}$ in number in the smartphone use. Above $50 \%$ of worldwide population uses smartphone. The aim of the study is to find the effect of smartphone addiction on craniovertebral angle and muscle fatigue of Cervical Erector Spinae (CES) and Upper Trapezius (UT). Eighty-six healthy students took an interest in the examination. Subjects were chosen for the study with the assistance of SAS-LV form. Lateral postural assessment was done to measure CVA with the assistance of photography method. Electromyography (EMG) was utilized to compute muscle fatigue of cervical erector spinae and upper trapezius. The co-relation coefficient between addiction and CVA is $r=-0.2196$, that means as SAS-LV score rises, the CVA decreases. Co-relation between addiction score and mean frequencies of UT and CES by $r=0.03679$ and $r=-0.04472$ respectively, this states that as addiction score increases UT shows fatigue however not CES. Co-relation between CVA and muscle fatigue of CES and UT by $r=0.01816$ and $r=-0.04472$ respectively, that means as CVA increases UT shows fatigue but not CES. There is co-relation between smartphone addiction, CVA and UT and CES fatigue but it is not statistically significant ( $p>0.05$ ). From the statistics, it is concluded that unnecessary utilization of smartphone decreases the CVA and muscle fatigue starts to set in, in the UT however not in CES. As the CVA decreases upper trapezius shows fatigue however not cervical erector spinae.
\end{abstract}

Keywords: Cervical Erector Spinae, Craniovertebral Angle, Electromyography, Muscle Fatigue, Smartphone Addiction, Upper Trapezius

\section{Introduction}

Addiction is a disorder with serious impacts on physical and mental health. A behaviour may have a comparable introduction as habit as far as over the top use, drive control issues, and contrary outcomes, however that doesn't imply that it ought to be viewed as an addiction. Emphasis ought to be placed on, moving away from the rigid structure when considering technological practices and utilizing different terms, for example, "hazardous use" to portray them. Recommendation of the, innovation use is to be concentrated in its sociocultural setting with an expanded attention on its compensatory capacities, inspirations, and gratifications ${ }^{15}$. The utilization of smartphone in static situation with unsupported arm prompts unusual arrangement of neck and shoulders. People bend their neck to look at the screens as a result there is increase work load on neck extensor muscles mainly
Upper Trapezius (UT) and Cervical Erector Spinae (CES). It likewise builds load, diminishes work limit and impacts the musculoskeletal system ${ }^{11,12}$. The load put on the CES and Trapezius muscle increases during these exercises and to keep the neck in a balanced position ${ }^{6}$. Upper trapezius is a superficial muscle and CES is profound paraspinal muscle, both of these muscles are stabilizers of cervical spine when neck is extended ${ }^{6}$. Craniovertebral angle is measured to evaluate the head posture of an individual ${ }^{16}$. It is the angle between the straight line and line drawn from tragus of the ear to spinous process of $\mathrm{C} 7$ vertebrae. ${ }^{21,22}$. A healthy cervical vertebrae presents with a lordotic (apex anteriorly) curve. There is, a forward inclination during utilization of smartphone by the user. CES and UT present at the posterior aspect of the neck extend to an extreme, as a result there is substantial burden and weight on cervical vertebrae $^{23}$. In typical healthy individuals, craniovertebral angle is about 49.9 degrees. Muscle fatigue represents a

${ }^{*}$ Author for correspondence 
complex phenomenon which is created because of a chain of metabolic, underlying and vicious changes in muscles due to insufficient oxygen and nutritive substances supply through blood course, just subsequent of changes in the efficiency in nervous system. The anatomical site of neuromuscular exhaustion can be grouped under three headings: (1) central fatigue (2) exhaustion of the neuromuscular intersection and (3) muscle exhaustion" ${ }^{19}$. The typical term "muscle fatigue" meaning indeed "local muscle fatigue" 16 is comparable with, "neuromuscular" fatigue. Time during which an individual is capable to perform certain work, such as keeping a demanded level of static (isometric) contraction is known as "mechanical indication of muscle fatigue" and might be defined as a "failure to sustain the required or anticipated force"13 or "any activity incited decrease in the maximal ability to produce power or force output" . Fatigue during muscle contraction is reflected in properties of myoelectric signals which are recorded on the surface of the skin over the muscles concerned ${ }^{20}$. With the assistance of surface electromyography, myoelectric signals emerging from the muscles are recorded, yet it has constraints like obstruction of the myoelectric signals from the neighboring muscles $^{3}$, in this way to determine local muscle fatigue this technique is used more frequently than some other significantly for the number of benefits it has. The benefits, henceforth, in this regard are (1) non-intrusiveness, (2) application in situ, (3) constant exhaustion observed during the presentation of defined work, (4) capacity to screen fatigue of a specific muscle and (5) relationship with biochemical and physiological changes in muscles during fatiguing. A lot of researches in the past show confirmations in regards to the derogatory impact of smartphone over-utilization on mental perspective as well as on the physical aspect of a person. The upper extremity and the cervical region being the most compromised while utilizing such gadgets on along term premise. However, a clear picture on the scenarios is not available. Hence, an attempt at building up a reasonable relationship between smartphone addiction with craniovertebral angle and muscle exhaustion of main stabilizers of neck is attempted.

\section{Materials and Methods}

Study Design: Cross sectional study.

Subjects: A random selection strategy was utilized in recruiting members for this study, a complete of 86 students opted from the Department of physiotherapy, KIMSDU, Karad.

Materials: SAS-LV Poll, Pen, Paper, Camera (Sony lens G30X), EMG Instrumentation, Assent Structure, Information Assortment Sheet, PC.

Method: A complete of 86 Students in the age range of 18-22 years were selected according to the inclusion standards and subject were acquainted with the investigation.

\section{Exclusion criteria:}

(i) Neck and upper extremity pathologies.

(ii) Careful history of the neck or shoulder surgery.

(iii) Indications with respect to any psychiatric disorder.

The Subjects then undersigned a composed consent form where the entire procedure for the investigation was explained to them. The investigation got approval from Institutional Ethical Committee KIMSDU before members enlistment started. Outcome measures were performed and Data analysis was done.

\section{Outcome Measures}

\section{1SAS-LV}

The present questionnaire shows 33 questions in regards to cell phone uses each question has 6 options, subjects had to mark appropriate option. Maximum score is 198. However, anyone scoring $>90$ is an addict.

\subsection{Photographic Method}

The photographic technique was utilized to gauge the craniovertebral angle. The subject was approached to sit on the stool with erect spine infront of a completely plain wall and two adhesive markers were set, 1 on the tragus of the ear and another on the $\mathrm{C} 7$ spinous process. The participants were photographed in lateral view utilizing SONY GX30 camera, the distance among the camera and subject is 1.5 meters. The photos were then analysed on Kinovea computer program to assess $\mathrm{CV}$ angle ${ }^{8}$. The photographic method has shown moderate to good reliability ${ }^{18}$.

\subsection{Electromyography}

Electromyography was used as a quantifying instrument for the, estimation of level of fatigue in UT and CES. The subjects were told to attain a prone position with the head outside the plinth, the surface was cleaned and cathodes were put on the motor point of upper trapezius initially with the inactive anode set at spinous process of $7^{\text {th }}$ cervical vertebra. The subject was then asked to shrug the shoulder and hold up till the point they couldn't further carry the activity and the duration of holding shrug was noted along with EMG reading. Also, for the cervical erector spinae the cathodes were put on the behind the neck and the subject was requested to hold the neckup till where the activity can't be performed further. The reading was then taken and statistically analysed to set up a co-relation that was hypothesised at the start of the study. 


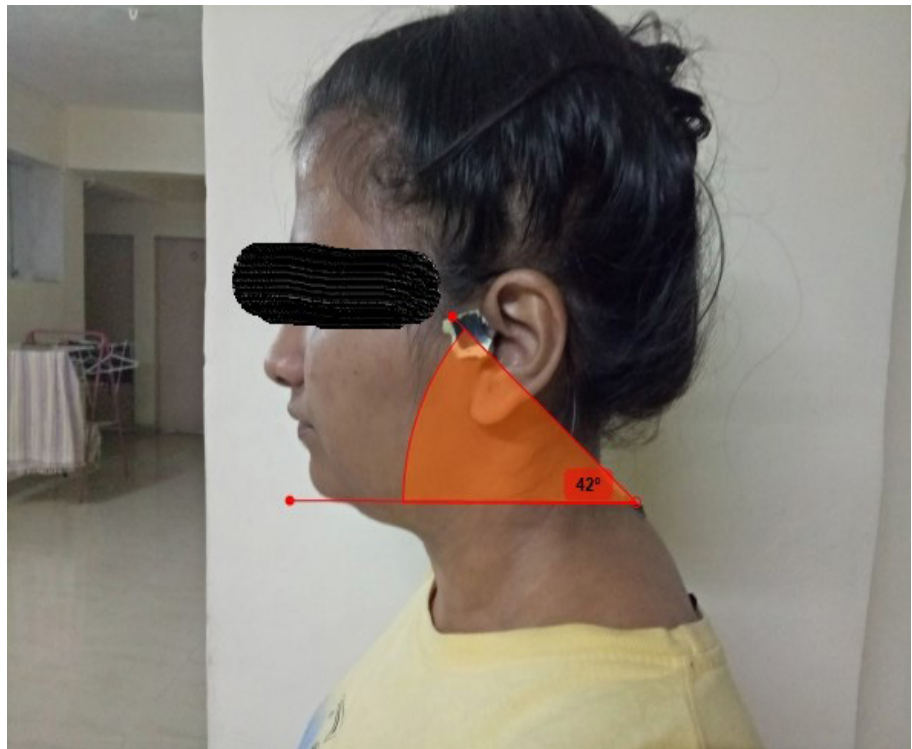

Figure 1. The photograph taken of a subject through photographic method and CVA is measured.

\section{Results and Discussion}

Table 1. Co-relation between addiction score and CVA

\begin{tabular}{|l|l|l|l|}
\hline $\begin{array}{l}\text { Correlation } \\
\text { coefficient(r) }\end{array}$ & $\mathbf{r}^{2}$ & p-value & $\begin{array}{l}\text { 95\% confidence } \\
\text { interval }(\mathbf{C I})\end{array}$ \\
\hline-0.2196 & 0.048 & 0.19 & -0.5113 to 0.1175 \\
\hline
\end{tabular}

${ }^{\star}$ Not significant $(\mathrm{p}>0.05)$

The Table 1 shows co-relation between smartphone addiction and CVA by $r=-0.2196$, we state that as the SAS-LV score increases angle decreases its value. But it is not statistically significant.

Table 2. Co-relation between addiction score and UT and CES mean frequencies (Muscle Fatigue)

\begin{tabular}{|l|c|c|c|c|}
\hline Muscles & $\begin{array}{c}\text { Correlation } \\
\text { coefficient(r) }\end{array}$ & $\mathbf{r}^{2}$ & $\mathbf{p}$-value & $\begin{array}{c}\mathbf{9 5 \%} \\
\text { confidence } \\
\text { interval } \\
\text { (CI) }\end{array}$ \\
\hline $\begin{array}{l}\text { Upper } \\
\text { Trapezius } \\
\text { (UT) }\end{array}$ & 0.03679 & 0.01353 & 0.8313 & $\begin{array}{c}-0.5113 \text { to } \\
0.1175\end{array}$ \\
\hline $\begin{array}{l}\text { Cervical } \\
\text { erector } \\
\text { spinae } \\
\text { (CES) }\end{array}$ & -0.04472 & 0.002 & 0.7956 & $\begin{array}{c}-0.3679 \text { to } \\
0.2881\end{array}$ \\
\hline
\end{tabular}

${ }^{*}$ Not significant $(\mathrm{p}>0.05)$
The Table 2 shows the correlation between addiction score with mean frequencies of UT and CES muscles by $r=0.03679$ and $r$ $=-0.04472$ respectively. Co-relation coefficient of smartphone addiction and UT is positive that means as the SAS-LV score increases, UT shows muscle fatigue, whereas CES does not show the same result.

Table 3. Co-relation between CVA and UT and CES mean frequencies

\begin{tabular}{|l|c|c|c|c|}
\hline Muscles & $\begin{array}{c}\text { Correlation } \\
\text { coefficient(r) }\end{array}$ & $\mathbf{r}^{2}$ & p-value & $\begin{array}{c}\mathbf{9 5 \%} \\
\text { confidence } \\
\text { interval } \\
\text { (CI) }\end{array}$ \\
\hline $\begin{array}{l}\text { Upper } \\
\text { Trapezius } \\
\text { (UT) }\end{array}$ & 0.1816 & 0.03297 & 0.2892 & $\begin{array}{c}-0.1564 \text { to } \\
0.4815\end{array}$ \\
\hline $\begin{array}{l}\text { Cervical } \\
\text { erector } \\
\text { spinae } \\
\text { (CES) }\end{array}$ & -0.07688 & 0.0059 & 0.6558 & -0.3955 to \\
\hline
\end{tabular}

${ }^{\star}$ Not significant $(\mathrm{p}>0.05)$

The Table 3 shows co-relation between CVA and the level of muscle fatigue of UT and CES by $r=0.1816$ and $r=-0.07688$ respectively. We state that, as the CVA increases fatigue starts to set in, in UT but similar comment cannot be done about CES.

The research which was undertaken to determine the effect of smartphone addiction on craniovertebral angle and muscle fatigue of cervical erector spinae and upper trapezius. According to Eom et al., over $18.8 \%$ show symptom in their early 20's of musculoskeletal disorders from cellphone usage along with experiencing pain with overuse of the same. In the research, there has been use of SAS-LV to find smartphone addicts among undergraduates. The lateral posture assessment was done using the photographic method for the assessment of CVA. Surface electromyography (sEMG) was done to find the UT and CES muscles fatigue by putting electrodes at appropriate positions. CES and UT are the main stabilizers of the neck and shoulder ${ }^{24}$. In an EMG finding, above 5\% muscle activities are increased when using visual display terminals ${ }^{6}$. This shows that use of visual display terminals can lead to fatigue of neck and shoulders. In the research it was stated there exist co-relation between all the components taken into consideration by the researcher in the present study. Conclusion being, that as the addiction score elevates the CVA decreases, but not significant statistically $(p>0.05)$. Upper trapezius shows fatigue with elevation of addiction score as well as CVA but not significant statistically $(\mathrm{p}>0.05)$. However, 
CES displays no fatigue with increase in addiction score and craniovertebral angle, but not significant statistically ( $\mathrm{p}>0.05)$. Neumann et al. observed that there is a lack of inter relation between CVA and scapular dyskinesis, which implies that participants with abnormal (low) CVA have abnormal (high) scapular dyskinesis due to an increase in CVA causes weakness in middle trapezius and serratus anterior which inturn leads to excessive load on $\mathrm{UT}^{10,14}$. Thus upper trapezius goes into fatigue. According to Sangyoung et al., muscle fatigue was shown in right UT and left UT were highest at cervical flexion angle of 50 degree and lowest at 30 degrees. These findings confirm that UT shows fatigue with change in cervical flexion angle but not CES. According to Kim et al., muscle fatigues more readily when looking downwards as compared to while looking forward ${ }^{7}$. Therefore, improving posture while using smartphone will decrease the muscle fatigue. There is increasing addiction towards smartphone whether known or unknown by a person leading to a lot of musculoskeletal changes that are troublesome in day to day activity. A comparison amongst the structural changes and muscular fatigue due to compulsive usage of the devices is a refreshing outlook of the research. A limitation of this study was that, it was not possible to use needle electrode for the recording exact myoelectric signals of CES and UT due to its cost ineffectiveness and invasiveness. This was conducted for short period of time with a smaller number of subjects because of Covid-19. Future studies should use needle electrodes to avoid interference of myoelectric signals between muscles.

\section{Conclusion}

According to the study results that were acquired, we can clearly relate that an elevation in the addiction score i.e., problematic increased use of smartphone can have derogatory effects on craniovertebral angle, to put it simply as the SAS-LV score increases the CVA decreases; and fatigue starts to set in UT, however similar conclusion cannot be made CES owing to the anatomically deep placement an invasive process like the needle electrode could draw a clear picture. However, the conclusion was not significant statistically research involving a large population could get statistical significance.

\section{Acknowledgement}

We acknowledge the support from KIMSDU, Karad. We are grateful to the research cell of KIMSDU for granting us permission to conduct the research. We would also like to acknowledge the Department of Physiology at KIMSDU for their support and valuable time. Acknowledgement to the Faculty of Physiotherapy.

\section{References}

1. Anjana J, Shinde M, Pawar A, Prasad P, Babu LK. Addiction of smartphone and depression within undergraduate students. Journal of Critical Review. 2020; 7(6):789-95. https://doi. org/10.31838/jcr.07.06.137

2. Chaffin DB. Localized muscle fatigue-definition and measurement. Journal of Occupational and Environmental Medicine. 1973; 15(4):346-54.

3. De Luca CJ. Myoelectrical manifestations of localized muscular fatigue in humans. Critical Reviews in Biomedical Engineering. 1984; 11(4):251-79.

4. Edwards RH. Human muscle function and fatigue. Ciba Foundation symposium. 1981; 82:1-18. https://doi. org/10.1002/9780470715420.ch1

5. Farina D, Merletti R, Indino B, Nazzaro M, Pozzo M. Surface EMG crosstalk between knee extensor muscles: Experimental and model results. Muscle and Nerve. 2002; 26(5):681-95. https://doi.org/10.1002/mus.10256. PMid:12402291

6. Greig AM, Straker LM, Briggs AM. Cervical erector spinae and upper trapezius muscle activity in children using different information technologies. Physiotherapy. 2005; 91(2):119-26. https:// doi.org/10.1016/j.physio.2004.10.004

7. Kim YG, Kang MH, Kim JW, et al. Influence of the duration of smartphone usage on flexion angles of the cervical and lumbar spine and on reposition error in the cervical spine. PhysTherKor, 2013; 20:10-17. https://doi.org/10.12674/ptk.2013.20.1.010

8. Kwon M, Kim DJ, Cho H, Yang S. The smartphone addiction scale: development and validation of a short version for adolescents. PLoS One. 2013; 8(12). https://doi.org/10.1371/journal. pone.0083558. PMid:24391787. PMCid:PMC3877074

9. Lee S, Lee D, Park J. Effect of the cervical flexion angle during smart phone use on muscle fatigue of the cervical erector spinae and upper trapezius. Journal of Physical Therapy Science. 2015; 27(6):1847-9. https://doi.org/10.1589/jpts.27.1847. PMid:26180333. PMCid:PMC4499996

10. Ludewig PM, Cook TM. Alterations in shoulder kinematics and associated muscle activity in people with symptoms of shoulder impingement. Physiotherapy. 2000; 80:276-91. https://doi. org/10.1093/ptj/80.3.276. PMid:10696154

11. Mekhora K, Liston CB, Nanthavanij S, Cole JH. The effect of ergonomic intervention on discomfort. 2000; 26(3):367-79. https://doi.org/10.1016/S0169-8141(00)00012-3

12. Mekhora K, Liston CB, Nanthavanij S, Cole JH. The effect of ergonomic intervention on discomfort in computer users with tension neck syndrome. International Journal of Industrial Ergonomics. 2000; 26(3):367-79.

13. Merletti R, Farina D. Myoelectric manifestations of muscle fatigue. Wiley Encyclopedia of Biomedical Engineering. 2006. https:// doi.org/10.1002/9780471740360.ebs1427. PMCid:PMC2870513

14. Neumann DA. Kinesiology of the musculoskeletal system: foundations for physical rehabilitation. 1st ed. Mosby: St Louis; 2015. p. 298-304.

15. Panova T, Carbonell X. Is smartphone addiction really an addiction? Journal of Behavioral Addictions. 2018; 7(2):252- 
9. https://doi.org/10.1556/2006.7.2018.49. PMid:29895183. PMCid:PMC6174603

16. Salahzadeh Z, Maroufi N, Ahmadi A, Behtash H, Razmjoo A, Gohari M, Parnianpour M. Assessment of forward head posture in females: Observational and photogrammetry methods. Journal of back and musculoskeletal rehabilitation. 2014; 27(2):131-9. https://doi.org/10.3233/BMR-130426. PMid:23963268

17. Schüldt K, Ekholm J, Harms-ringdahl KA, Németh G, Arborelius UP. Effects of changes in sitting work posture on static neck and shoulder muscle activity. Ergonomics. 1986; 29(12):1525-37. https://doi.org/10.1080/00140138608967266. PMid:3816746

18. Lee J, Lee Y, Kim H, Lee J. The effects of cervical mobilization combined with thoracic mobilization on forward head posture of neck pain patients. Journal of Physical Therapy Science. 2013; 25(1). https://doi.org/10.1589/jpts.25.7

19. vanNiekerk SM, Louw Q, Vaughan C, Grimmer-Somers K, Schreve K. Photographic measurement of upper-body sitting posture of high school students: a reliability and validity study. BMC Musculoskelet Disord. 2008; 9:113. https://doi.org/10.1186/14712474-9-113. PMid:18713477. PMCid:PMC2542508

20. Vøllestad NK. Measurement of human muscle fatigue. Journal of Neuroscience Methods. 1997 27; 74(2):219-27. https://doi. org/10.1016/S0165-0270(97)02251-6
21. Watson DH, Trott PH. Cervical headache: An investigation of natural head posture and upper cervical flexor muscle performance. Cephalalgia. 1993; 13(4):272-84. https://doi.org/10.1046/j.14682982.1993.1304272.x. PMid:8374943

22. Wilmarth MA, Hilliard TS. Measuring head posture via the craniovertebral angle. OrthopPhysTherPract. 2002; 14:13-15.

23. Yip $\mathrm{CH}$, Chiu TT, Poon AT. The relationship between head posture and severity and disability of patients with neck pain. Manual Therapy. 2008;13(2):148-54. https://doi.org/10.1016/j. math.2006.11.002. PMid:17368075

24. Zhang FR, He LH, Wu SS, et al. Quantify work load and muscle functional activation patterns in neck-shoulder muscles of female sewing machine operators using surface electromyogram. Chinese Medical Journal. 2011; 124:3731-37.

25. Eom SH, Choi SY, Park DH: An empirical study on relationship between symptoms of musculoskeletal disorders and amount of smartphone usage. Journal of the Korea Safety Management \& Science. 2013; 15:113-20. https://doi.org/10.12812/ksms.2013. 15.2.113 